suggest that we dry our hands properly before applying gloves, forget about the extra powder, and starch granulomatosis of the peritoneum should become a disappearing disease.-I am, etc.,

Halifax

GeOFFREy HyMAN

\section{Deglycyrrhizinized Liquorice in Duodenal Ulcer}

SIR,-We read with considerable interest the results of the multicentre trial on the treatment of duodenal ulcer with glycyrrhizinicacid-reduced liquorice (28 August, p. 501). No beneficial effect on the course of an acute relapse of chronic duodenal ulcer could be attributed to the liquorice preparation. It is now undisputed that deglycyrrhizinized liquorice accelerates the healing of gastric ulcer, ${ }^{1-2}$ but its mode of action is unknown.

We have recently studied the effect of this drug on gastric acid secretion. Twelve male patients with proved duodenal ulcer were given deglycyrrhizinized liquorice (Cedona) in a dose of $760 \mathrm{mg}$ t.i.d. for a period of one week. Maximal gastric acid output using pentagastrin as the stimulus was measured before and after treatment. Acid levels before treatment were compatible with those found in duodenal ulcer: no significant change was detected in the corresponding levels after the seven-day period.

Though this was a short-term trial, there was clearly no evidence of any immediate effect on gastric acid secretion. The acceleration in healing of gastric ulcers in the presence of deglycyrrhizinized liquorice implies a prompt pharmacological action. It is therefore unlikely that any change in gastric acid secretion can account for the ulcerhealing properties of this liquorice preparation.-We are, etc.,

B. Whiting

Department of Materia Medica,

University of Glasgow,

Glasgow N.1

1 Russell, R. I., and Dickie, J. E. N., fournal of Therapeutics and Clinical Research, 1968, 2,2 .
Tewari, S. N., and Trembalowicz, F. C., Gut,
1968, 9, 48. 3 Turpie, A. G. G., Runcie, J., and Thomson, T. J., Gut, 1969, 10, 299.

\section{Treatment of Opium Addiction}

SIR,-I was interested to read Dr. C. L. Anand's letter (11 September, p. 640) describing the use of an extract of green oats (Avena sativa) in the treatment of opium addiction.

This form of therapy is known by doctors practising homoeopathy and was described almost 70 years ago in Clarke's Materia Medica." There it states "Avena has been used empirically in substantial doses $(5$ to 15 drops of the tincture, preferably in hot water) in a large number of cases of nerve weakness. . . It is most valuable in enabling a patient to overcome the morphine habit. It appears to exert the same kind of soothing action, without creating a habit of its own. When not more than four grains of morphine have been taken daily it may be discontinued abruptly, 15 drops of Avena in a wineglass of hot water being given four times a day instead. The only symptom that has been observed to be caused by it is a pain at the base of the brain from 20 -drop doses."

In the 1962 edition of Clarke there is an addition "An alkaloid, Avenin $\left(\mathrm{C}_{* i 1} \mathrm{H}_{31} \mathrm{NO}_{1 *}\right)$, has been isolated from oats. It is easily soluble in alcohol. No clinical observations with this have been recorded."'

The same treatment is mentioned by Boericke in his Materia Medica, ${ }^{3}$ and he states it is best used in material doses, and among other indications for the drug lists alcoholism and insomnia in alcoholics.-I am, etc.

Bromsgrove, Worcs

R. A. F. JACK

Clarke, J. H., A Dictionary of Practical Materia Medica. London, Homoeopathic Publishing Co. 1902 .

2 Clarke, J. H., A Dictionary of Practical Materia Medica, 3rd edn. Rustington, Health Science Press, 1962.

Boericke, W., Pocket Manual of Homoeopathic Materia Medica, 9th edn. New York, Boericke and Runyon, 1927.

\title{
Maternal Oestrogen Levels During Penicillin Treatment
}

SIR,-Corticosteroids ${ }^{1}$ and ampicillin $^{2}$ are found to decrease the oestrogen excretion in pregnant women. Because different penicillins are widely used during pregnancy and the estimation of urinary oestrogens as a measure of the welfare of the fetoplacental unit is used increasingly, we studied the effect of phenoxymethylpenicillin in a dose of $653 \mathrm{mg}$ orally every 8 hours on the urinary ${ }^{3}$ and plasma $^{2}$ oestrogens in six mothers $38-40$ weeks pregnant. The results can be seen in the Table.

\section{Accident and Emergency Services}

SIR,-The name "accident unit" in district hospitals is a misnomer. These units receive the emergencies of medicine in its widest possible sense but are without beds, and the role of those working in them is to diagnose and resuscitate. This requires space, a trolley, tools, and expertise. Expertise means an overall knowledge of diagnosis in every branch of medicine, together with a clear understanding of both the physiological and practical aspects of resuscitation. The application of such expertise should enable the doctor in this situation to know which special department, or departments, to call on and to what area the patient should go from the accident department.

We maintain that such a doctor must have a higher qualification, have training in resuscitation, and be of consultant status with an adequate number of junior staff. In the district hospital he would be, with his staff, the consultant immediately concerned with diagnosis and resuscitation of emergencies-cases which form $70 \%$ of all hospital admissions. He would not be directly concerned with intensive care, which is quite different from resuscitation, nor with follow through treatment.

Such a consultant would have a status equal to his colleagues in other specialties, with an acknowledged and respected expertise which would help create and sustain a department essential to and interlocking

TABLE.-Oestrogen excretion and plasma oestriol in six non-infected pregnant women treated with phenoxymethylpenicillin-K orally, $653 \mathrm{mg}$ every 8 hours, on days 3,4 , and 5 .

\begin{tabular}{|c|c|c|c|c|c|c|c|c|c|}
\hline Day & .. & .. & . & $1+2$ & 3 & 4 & 5 & 6 & 7 \\
\hline Urine* & . & . & .. & $38 \pm 5 \cdot 8$ & $36 \pm 9 \cdot 0$ & $30 \pm 9 \cdot 0$ & $29 \pm 7.5$ & $41 \pm 3 \cdot 4$ & $47 \pm 12.4$ \\
\hline Plasma ${ }^{\dagger}$ & .. & & .. & $21 \pm 3 \cdot 0$ & $23 \pm 5.9$ & $16 \pm 3 \cdot 4$ & $11 \pm 3 \cdot 3$ & $20 \pm 3.9$ & $24 \pm 6.4$ \\
\hline
\end{tabular}

*Urinary oestrogens $\mathrm{mg} /$ day. Mean $\pm \mathrm{S} . \mathrm{E}$.

†Plasma oestriol, $\mu \mathrm{g} / 100 \mathrm{ml}$. Mean \pm S.E.

There was a relative decrease of urinary oestrogen excretion of $32 \%$ during the second and third day of penicillin treatment $(\mathrm{p}<$ $0.01)$; plasma oestriol decreased $48 \%$ ( $<<$ $0.001)$. In an earlier study, ${ }^{2}$ we found that ampicillin also decreased both the plasma oestriol and oestrogen excretion during pregnancy, and that ampicillin did not produce any chemical reaction which could affect the determination methods. Therefore, one can assume that phenoxymethylpenicillin decreases the production of oestrogens in the fetoplacental unit or causes changes in placental permeability to oestrogens. This phenomenon seems to be bound in the penicillanic unit itself, because ampicillin and phenoxymethylpenicillin have the same effect. Decreased oestrogen excretion was not observed to cause any harm to the fetus or delivery. Thus, when determining urinary oestrogens, it would be wise to ask the patient whether she has recently been on penicillin.-We are, etc.

\section{Martti Pulkkinen}

K. Willman

Department of Obstetrics and Gynaecology

and Clinical Chemistry,

University of Turku,

\section{Finland}

1 Warren, J. C., and Cheatum, S., fournal of Willman, Endocrinology, 1967, 27, 433.

., and Pulkkinen, M., American fournal of Obstetrics and Gynecology, 1971, 3 Nordström, C. G., Clinica Chimica Acta, 1968, with all other hospital denartments. His specialty would be as "consultant in accident medicine."

May we suggest that those colleges and associations closelv concerned be acked to examine this possible solution to what has been for a long time a major problem in the National Health Service.-We are, etc.,

\section{W. BRACEY}

R. E. LODER

Peterborough District Hospital, Peterborough

SIR,- The function of accident and emergency departments has not been clearly defined. I believe it is wishful thinking to assume that we can change the character of the work, although it is likely with more career grade medical officers in post that the number of cases more suitable for general practitioner or outpatient department care would decrease.

The role of the department should be diagnosis and assignment to the correct specialty, only essential first-aid being given. Because of the wide range of the work the doctor in the casualty officer's seat should not be a specialist, but someone of wide general experience. It is the quality of the doctor in this "hot seat" and not the consultant in administrative charge that will largely determine the quality of service. To 